NOTICIAS Y COMENTARIOS 


\title{
SEQUÍAS EN EL SURESTE DE LA PENÍNSULA IBÉRICA: CAMBIOS EN LA PERCEPCIÓN DE UN FENÓMENO NATURAL
}

\author{
Alfredo Morales Gil \\ Antonio M. Rico Amorós
}

\begin{abstract}
RESUMEN
La sequía que padecen las tierras del sureste de la Península Ibérica ha devuelto a la actualidad la importancia que tiene este hecho natural para el desarrollo de las actividades humanas. Lejos del discurso catastrofista de la controvertida hipótesis del cambio climático planetario, en este estudio-comentario se ofrece una reflexión acerca de sus causas y consecuencias que, cada vez más, evidencian las limitaciones que introduce la aridez en este territorio en relación con la ausencia de una planificación racional de las actividades económicas (regadío, urbanización y turismo) coordinada con la previsión de unas actuaciones realistas sobre las disponibilidades hídricas.
\end{abstract}

\begin{abstract}
The drought that suffer the lands of the southeast of the Iberian Peninsula has returned to the present time the importance that has this natural fact for the development of the human activities. Far of the negative speech about the controverted hypothesis of the planetary climatic change, in this commentary study is offered a reflection about its causes and consequences which, increasingly evidence, the limitations that introduces the aridity in this territory in relationship to the absence of a rational planning of the economic activities (irrigable, urbanization and tourism), coordinated with the provision of some realistic performances on the water availabilities.
\end{abstract}

Durante las últimas décadas, las fluctuaciones naturales que se producen en el ritmo de las precipitaciones, propias de los climas de filiación mediterránea dominantes en gran parte del territorio peninsular, han puesto en evidencia las disfuncionalidades tan grandes que median entre unos recursos de agua muy escasos y unas necesidades por parte del hombre en permanente crecimiento. Así, no sólo en las tierras de la España Seca, sino 
también en muchas regiones de la Húmeda, se presentan anomalías en los abastecimientos urbanos e industriales manifestando la ausencia de una planificación adecuada a las disponibilidades de agua que resulte compatible con el desarrollo socioeconómico previsto para las diferentes regiones peninsulares.

En la explicación del fenómeno natural de las sequías están proliferando opiniones catastrofistas que encuentran intencionada y desafortunada respuesta en la pretendida disminución de lluvias que acompañaría la hipótesis del cambio climático planetario en las tierras ibéricas. No debe extrañar que este estado de opinión se halle tan difundido y asumido entre la gente, más todavía cuando estos últimos años han proliferado las manifestaciones más o menos científicas, con asiduo abuso de hipótesis y modelos apriorísticos, que amenazan a la humanidad con grandes cataclismos meteorológicos, entre los cuales destaca el recalentamiento de la tierra. En el sureste de la Península Ibérica se augura que la elevación de temperaturas y el consiguiente aumento de la evaporación provocarán la existencia de grandes áreas todavía más secas sobre las que avanzará, como una plaga apocalíptica, el desierto.

A todo esto, cabría reflexionar sobre si ese cambio climático no podría hacer que zonas actualmente secas se volviesen más húmedas, como ya sucedió con las fluctuaciones cuaternarias en el Sáhara donde con condiciones de semiaridez se desarrollaron unos sistemas bióticos de gran valor.

Lo cierto es que este proceder, difundido en ocasiones por populares pseudocientíficos amparados, ocasionalmente, en grandes proyectos de investigación, se ha visto alentado y aireado por algunos medios de difusión informativa que han contribuido a crear una imagen distorsionadora de la realidad, muy alejada de la verdad y repleta de incertidumbres. Frente a éstos, estudios científicos de larga gestación y callada realización han demostrado y confirmado, con resultados contrastados y acertados, que no se puede aseverar ninguno de estos postulados, al coincidir en que se trataría de fluctuaciones naturales en el ritmo anual e interanual de las precipitaciones y temperaturas, tal y como se han dado ya en otras épocas. En cualquier caso, la insuficiente cobertura territorial de la red de observatorios meteorológicos y la ausencia, en la mayoría de ellos, de series cronológicas de al menos treinta años, hace inviable y muy compleja la obtención de resultados fiables y concretos que corroboren el supuesto cambio climático a que se alude.

Mientras tanto, a los políticos y gobernantes, de todo signo y tendencia, les acomoda la existencia de esta confusión para enmascarar las malas planificaciones realizadas o la carencia de ellas para preveer los efectos de estas fluctuaciones climáticas.

Condicionada por factores hidrográficos y climáticos, se articula una realidad geográfica indiscutible que convierte al sureste ibérico en una de las regiones naturales peninsulares donde el fenómeno de la sequía se manifiesta con mayor frecuencia y gravedad. A sotavento de la gran zona de circulación atmosférica general del oeste y con un fenómeno foehn acusado por efecto del bastión montañoso de las béticas, los registros pluviométricos de este territorio no suelen exceder de $300 \mathrm{~mm}$. convirtiendo a esta región climática en la más seca de la Península Ibérica. Aridez, elevada irregularidad de las lluvias, sequía estival extrema y gran concentración horaria de las lluvias se acompañan, empero, de unas aptitudes térmicas excelentes para la práctica de la agricultura. La temperatura media mensual más fría no desciende por debajo de $8^{\circ} \mathrm{C}$, la amplitud térmica no excede de $18^{\circ} \mathrm{C}$, la media anual supera $\operatorname{los} 16^{\circ} \mathrm{C}$ y los valores de insolación efectiva se aproximan bastante a tres mil horas anuales ${ }^{1}$.

1 GIL OLCINA, A.: "Rasgos específicos del Sureste Peninsular". En Paralelo 37, (en prensa), Almería, 1995, 15 pp. 
Según estos umbrales quedarían incluidas en la región climática del sureste la mayor parte de las provincias de Almería, Murcia y Alicante. Más concretamente se englobarían las comarcas de la Marina Baja, Campo de Alicante, Bajo y Medio Vinalopó, Bajo Segura, Campo de Cartagena, Cuenca de Mula, Vega Media del Segura, Valle de Ricote, Bajo y Medio Guadalentín, Bajo y Medio Almanzora, Campo de Níjar, Bajo y Medio Andarax y Campo de Dalías.

\section{La sequía como hecho climático}

Las reducción de lluvias en un período seco, siempre superior a 16 meses, abre paso a una secuencia de indigencia pluviométrica entendida ésta como un episodio natural de las tierras del sureste ibérico, provocado por el predominio de circulaciones atmosféricas de filiación subtropical con efecto de subsidencia dinámica y ausencia de lluvias. Las situaciones sinópticas más comunes asociadas a estas circulaciones subtropicales se corresponden $\operatorname{con}^{2}$ :

1. Dorsal subtropical marítima: ubicación de una estructura anticiclónica sobre nuestras latitudes.

2. Cresta sahariana centrada o advección de la masa de aire sahariana.

3. Cresta sahariana mediterránea: advección de la masa de aire sahariana que afecta específicamente a la mitad oriental de la Península.

4. Circulaciones zonales con tránsito de borrascas del frente polar que se manifiestan en el sureste de la Península Ibérica con vientos catabáticos resecos y sin apenas lluvias.

Un aumento de la frecuencia de estos tipos de tiempo, por la estabilidad atmosférica que introducen, no favorece la aparición de lluvias, reduciendo en años secos el número de días de lluvia a 25 ó 30 cuando la media es de 50 días. Es habitual la disminución de las aportaciones de lluvia durante el otoño y la primavera, fundamentalmente las producidas por algún evento atmosférico de chubascos intensos, hecho que restringe la cuantía total de la precipitación registrada hasta un $40 \%$ o más incluso. En estas tres provincias es habitual que se produzca un año seco con registros de lluvia que no exceden del $60 \%$ de la media anual; aunque en series de indigencia pluviométrica con varios años secos encadenados no es condición indispensable dicho porcentaje, sino que con valores superiores, las producidas se muestran poco eficaces para restituir el equilibrio del ciclo hidrológico, sobre todo en su fase de escorrentía superficial, provocando de esa manera una disminución importante en la cantidad de recursos de agua a disposición del hombre.

El territorio que nos ocupa nunca ha escapado a estos avatares del tiempo atmosférico frente a los cuales el hombre siempre ha procurado actuar mediante el ingenio, aprovechando los escasos recursos de agua disponibles y adecuando las actividades productivas a los condicionantes impuestos por dichas situaciones. No obstante, son muchas y cada vez más percibidas por el hombre las secuencias de indigencia pluviométrica que han derivado en efectos de daños para las actividades humanas. En el presente siglo, destaca la que afectó a tierras alicantinas desde 1909 a 1914, que al solaparse a los efectos de la filoxera propició el abandono de unas 35.000 has. de viñedo y de otras 25.000 has. dedicadas al cultivo de cereal. Como resultado de esa coyuntura tan adversa, entre 1908 y 1913 unos

2 OLCINA CANTOS, J. y RICO AMORÓS, A.M.: "Sequías y golpes de calor en el sureste ibérico: efectos territoriales y económicos". En Investigaciones Geográficas n ${ }^{\circ} 13$, Instituto Universitario de Geografía, Universidad de Alicante, 1995, pp. 47-80. 
68.800 emigrantes, mayormente campesinos, salieron de Alicante con destino al norte de África ${ }^{3}$. Esa misma secuencia de sequía, que en tierras murcianas acabó en 1913 con un registro de 102,8 mm. según los datos del observatorio de Murcia, se reprodujo años más tarde, en 1924, y se prolongó hasta 1941, es decir, 18 años continuados en los cuales "la pertinaz" sequía asolaba las resecas tierras del sureste ibérico, concurriendo además una coyuntura tan desfavorable como la Guerra Civil y la postguerra.

Poco después, en 1945, el pluviométro de Murcia marcaba una cantidad mínima histórica con tan sólo 99,5 mm., aunque ese año seco, al mediar entre dos con lluvias ligeramente próximas o superiores a lo normal, no tuvo efectos tan dañinos como otras secuencias de sequía que, como es habitual, iban a retornar años más tarde. En efecto, en tierras murcianas y en el sur de la provincia de Alicante se percibieron con especial interés las de los períodos 1963-1964 y 1967-1968, que propiciaron, en auxilio de otros motivos que perseguían el desarrollo de esta región, la redacción del Anteproyecto General de Aprovechamiento Conjunto de los Recursos Hidráulicos del Centro y Sureste de España, Complejo Tajo-Segura, aprobado por el Gobierno el 13 de setiembre de 1968.

Más cercanas a la actualidad, son de mencionar el período de 1978-1984 y la todavía inconclusa sequía iniciada en 1993, considerada con absoluta exageración por parte de muchos medios de información como "la sequía del siglo", puesto que climáticamente desde luego no lo es, ni por duración ni por la escasez de lluvias como se está manifestando. Partiendo de la evidencia de que ninguna seca se parece a otra, la secuencia de indigencia pluviométrica de finales de los años setenta y principios de los ochenta, pese a estar salpicada de algún episodio excepcional de lluvias intensas como el ocurrido en tierras alicantinas del 19 al 21 de octubre de 1982, se manifestó con un balance de daños muchísimo mayor al provocado por las de mayor duración y escasez de lluvias ocurridas anteriormente. Según las estadísticas oficiales, los daños económicos en el sector agrario de las provincias de Alicante y Murcia ascendieron entonces a 35.000 millones de pesetas 4 .

Con una demanda de agua para usos urbanos en permanente expansión y una superficie de regadío que superaba las 300.000 has., la capacidad de regulación plurianual de los embalses de la Cuenca del Segura y los primeros volúmenes de agua trasvasados desde el Alto Tajo fueron incapaces de amortiguar los efectos de una sequía que en algunos observatorios como el de Murcia se manifestó con 4 años seguidos de lluvias muy inferiores a la media, ya que en ninguno de los años comprendidos entre 1981 y 1984 se superaron los $200 \mathrm{~mm}$., destacando los $159 \mathrm{~mm}$. de $1983^{5}$.

En esa secuencia seca se puso de manifiesto la carencia de una planificación racional capaz de dosificar adecuadamente los recursos hidráulicos a largo plazo, ya que en los primeros años de la misma los desembalses de recursos propios del Río Segura, almacenados durante el período de abundancia de lluvias comprendido entre 1971 y 1977, sumados a los primeros volúmenes de agua aportados por el Acueducto Tajo-Segura, fueron capaces de amortiguar la escasez de recursos de agua provocada por la escasez de lluvias, pero no en cambio en 1983 y 1984, donde coincidió una disminución de caudales trasvasados desde el Alto Tajo con unas reservas embalsadas en la Cuenca del Segura muy exiguas, que no fueron suficientes para satisfacer todas las demandas generadas los años precedentes.

3 BONMATÍ ANTÓN, J.F.: La emigración alicantina a Argelia. Universidad de Alicante, C.A.P.A. Murcia, 1989, 270 pp.

4 OLCINA CANTOS, J. y RICO AMORÓS, A.M.: op. cit. p. 61.

5 CONSEJERÍA DE FOMENTO Y TRABAJO: Anuario de la Región de Murcia. Tomo I. Datos Regionales. Comunidad Autónoma de la Región de Murcia, Murcia, 1994, p. 745. 
Sobre la reciente y todavía inconclusa secuencia de penuria pluviométrica iniciada en 1993, lo cierto es que habiendo transcurrido sólo dos años ésta ha planteado ya tantas o más disfuncionalidades que la última sequía de inicios de los años ochenta. Desde el punto de vista climático esta seca se inició en el otoño de 1993, con una reducción muy notable de lluvias en relación a lo que suele ser habitual en esta estación, en la cual llega a registrarse hasta el 50\% de la precipitación media anual. Así, en Murcia en el período que va de septiembre a diciembre de 1993 tan sólo se recogieron $64,8 \mathrm{~mm}$. cuando lo habitual es que se superen los $150 \mathrm{~mm}$. Lo mismo cabe decir de los observatorios de la mitad sur de la provincia de Alicante, donde el de Orihuela tan sólo recibió durante todo el año $200 \mathrm{~mm}$., es decir, un 67\% de lo habitual. En cambio, como es condigno de estas épocas de escasez de lluvias, en ese mismo año otros observatorios de la provincia superaron con creces el índice de precipitación media anual, destacando Alcalalí y Pego, con 1.205 y $1.261 \mathrm{~mm}$. respectivamente, lo que indica la necesidad de referenciar espacialmente, en su justa medida, el estudio de los efectos de las sequías.

En 1994 y lo que se lleva transcurrido de 1995 (hasta octubre) ha significado la generalización de la sequía a todo el territorio de la provincia de Alicante, de forma que en localidades como San Miguel de Salinas, Alicante, Orihuela e incluso en Denia, ese año se registraron lluvias por debajo de la mitad del índice de precipitación media anual. A mayor abundamiento, esa mengua tan acusada de precipitaciones se ha acentuado también en 1995, a falta de incluir las producidas durante los meses de noviembre y diciembre. La verdad es que se asiste a los efectos de un año excepcionalmente seco, en el cual algunos observatorios no habían alcanzado, hasta el mes de octubre inclusive, siquiera el $40 \%$ de la lluvia media anual. Sin embargo, pese a su excepcionalidad, se debe advertir que no son cantidades mínimas, ya que durante otras secuencias continuadas de años secos esos registros han sido rebajados. Así, el de Murcia había registrado $101 \mathrm{~mm}$. hasta octubre de 1995, superando ya, a falta de añadir las producidas en los dos últimos meses del año, a los 99,5 mm. que se registraron en 1945.

En cuanto a la duración de esta última sequía, como se ha comprobado, tan sólo han transcurrido 2 años, bastante alejada de los 7 que duró la de finales de los setenta y más todavía de los 18 de la que afectó a tierras murcianas desde 1924 a 1941. En cambio, al igual que se ha demostrado en toda la mitad sur de la Península Ibérica y en otras regiones con grandes colectores fluviales como Castilla-León (Duero) y Aragón (Ebro), dos años de sequía, sin ser los más secos, han bastado para poner en evidencia las graves carencias en infraestructura hidráulica, sobre todo en materia de aguas subterráneas y la falta de una planificación hidráulica racional que ha sido incapaz de adecuar, con el debido equilibrio, las demandas de recursos de agua a las disponibilidades naturales existentes en cada momento. De esa manera se ha contribuido a exagerar la percepción humana de la sequía como hecho climático.

\section{La sequía como hecho humano}

\subsection{Mutaciones cualitativas}

La percepción por parte del hombre de las secuencias de indigencia pluviométrica varía de un territorio a otro. Sin duda, donde siempre se ha tenido una mayor conciencia de este hecho natural ha sido en las regiones secas donde las producciones agrícolas variaban según el ritmo impuesto por las lluvias. Por contra, en los últimos treinta años, con los procesos de urbanización y expansión de la agricultura de regadío, hasta en estas tierras ha habido un cambio en la percepción de las sequías. 
El desarrollo urbano y el cambio de los modos de vida del hombre han ido más allá del límite de las ciudades hasta alcanzar zonas rurales. En éstas se han incorporado todas las comodidades suscitadas por la adopción de los modos de vida urbanos y, como un signo destacado de ellos se incluyen los sistemas de abastecimiento de agua potable. Se ha pasado así, tanto en las ciudades como, más recientemente, en el medio rural, de la fuente, el pozo y el algibe al grifo.

No sólo se hace uso del agua para las tareas domésticas, sino que además los recursos disponibles son ahora utilizados para otros fines como la limpieza de calles, riego de jardines y en ocio, sin ajustar los consumos a la escasez del agua. Resulta generalizado encontrar en la mayoría de parques públicos y privados especies, muchas veces de filiación húmeda-tropical, que demandan altas cantidades de agua, coincidiendo sus máximas exigencias en el verano cuando la estacionalidad del uso urbano-turístico eleva los consumos. Esa misma circunstancia se puede verificar en áreas rurales o en segundas residencias periurbanas donde la cultura del pozo, el aljibe o la fuente, ha dado paso a la del grifo, no sólo para los usos domésticos, sino también para las piscinas, jardines y el riego de pequeños huertos, derrochando así un agua muy escasa y de gran calidad.

En la agricultura también se han producido cambios cualitativos muy importantes en las fórmulas de acceso al agua para riego, manteniéndose de esa forma consumos muy elevados. De otro lado, los cambios experimentados en la selección de cultivos y su extraestacionalidad han motivado un aumento de la demanda de agua para una misma parcela. No es lo mismo cultivar las especies de la trilogía mediterránea en regadío, práctica habitual en las huertas tradicionales, que la implantación de especies arbóreas y hortícolas tropicales de cultivo ininterrumpido, pues éstas exigen unas mayores dotaciones de agua por hectárea y año.

De los regadíos históricos con aguas perennes derivadas por gravedad para las terrazas aluviales de cursos como el Segura, Vinalopó, Monnegre, Almanzora y Andarax, se ha pasado, sobre todo a partir de la década de los años sesenta, a otros sistemas de derivación mediante motobombas que extraen las aguas de los ríos y de los acuíferos subterráneos, además de impulsar cabezales de riego por aspersión, goteo, exudación, microaspersión,...

En estos casos, las aguas son elevadas y conducidas a terrenos muy alejados de los lechos de inundación. Se rompe de esta forma con la tradicional vinculación agua-tierra en aquellas propiedades más próximas a las corrientes de agua. Ahora la práctica agraria se traslada a bastantes kilómetros de distancia del lugar de captación del agua, buscando las tierras más fértiles, mejor avenadas, menos expuestas a los riesgos de heladas por advecciones septentrionales o por inversiones térmicas, más soleadas y, en ocasiones, menos agotadas de nutrientes y contaminadas de sales por la práctica de cultivos anteriores. Se genera, así, un nuevo paisaje agrario itinerante y muy cambiante de un año para otro, sobre todo en las producciones hortícolas, dependiendo su estado anual de las disponibilidades de agua para riego y de los mecanismos de comercialización que determinan la rentabilidad y la estacionalidad de las demandas.

\subsection{Cambios cuantitativos}

Además de esos cambios cualitativos en los hábitos de consumo urbanos y rurales, también ha habido otros de naturaleza cuantitativa, ya que el número de habitantes cuyos hogares están conectados a las redes de abastecimiento de agua potable, ha experimentado un gran aumento en el transcurso de este siglo. Así, mientras que en las tres provincias del sureste los efectivos demográficos existentes en 1900 ascendían a 1.407.000 habitantes, en 1991, según los datos del último censo, la población se había duplicado alcanzando la cifra 


\begin{tabular}{|lrrr|}
\hline PROVINCIAS & $\mathbf{1 9 0 0}$ & $\mathbf{1 9 7 0}$ & $\mathbf{1 9 9 1}$ \\
\hline Alicante & 470.149 & 920.105 & 1.334 .545 \\
Murcia & 577.987 & 832.313 & 1.059 .612 \\
Almería & 359.013 & 375.004 & 465.662 \\
\hline TOTAL & 1.407 .149 & 2.127 .422 & 2.859 .819 \\
\hline
\end{tabular}

Fuente: Nomenclátor de España de 1900 y Censos de Población de 1970 y 1991.

de 2.859.819 habitantes, con incrementos que han sido especialmente elevados en Alicante y Murcia - vid. cuadro $\mathrm{n}^{\mathrm{o}} 1$-.

Como resultado de este proceso de expansión demográfica se ha operado un aumento espectacular en el consumo de agua para abastecimiento público agudizado por el cambio en los hábitos urbanos de gasto. En el año 1900 el consumo medio por habitante y día era de 10 litros, lo que traducía unas exigencias de agua cifrables en $5.135 .550 \mathrm{~m}^{3} /$ año, mientras que en 1991, con una población que ha duplicado a la de principios de siglo, el consumo medio por habitante ha ascendido a 200 1/día. En definitiva, el consumo de agua de 1991 era cuarenta veces superior al de principios de siglo, arrojando un volumen de gasto total de $208 \mathrm{Hm}^{3} /$ año al cual se deben añadir $26,5 \mathrm{Hm}^{3} /$ año para los usos turísticos y otros $50 \mathrm{Hm}^{3} /$ año que precisarían los usos industriales. De esta forma, se alcanzaría un consumo medio anual de $285 \mathrm{Hm}^{3} /$ año para todos ellos. Este gran dinamismo demográfico y el aumento consiguiente de las necesidades de agua potable está manifestando la envergadura de unos procesos de puesta en valor del territorio de efectos a veces espectaculares.

El turismo ha sido, sin duda, una de las actividades con más implicaciones sobre el territorio surestino ya que éste se ha transformado mediante unos planteamientos donde primaban los intereses económicos. Por ello, los modelos urbanísticos a que ha dado lugar (laxos y de baja densidad), el aumento casi ininterrumpido de visitantes, la utilización del agua como recurso de recualificación del producto turístico (campos de golf) y actuaciones inmobiliarias ejecutadas casi siempre sin la garantía de suministro, ni la adecuación de las infraestructuras de distribución de agua potable y la red, constituyen algunos de los símbolos de un proceso que ha ayudado todavía más a agravar el déficit de recursos de agua. Basta advertir que la oferta extrahotelera existente en las tres provincias supera en la actualidad el millón de plazas, gran parte de ellas en municipios costeros de Alicante, mientras que la oferta total en hoteles (575 establecimientos) y en campings (80) ascendía en 1994 a 125.458 plazas, es decir, 62.814 plazas más que las existentes en el año 1972.

Pero al igual que en los usos urbanos del agua, en los agrarios también se ha producido un salto cuantitativo muy grande ya que las 137.523 has. existentes en el sureste peninsular a principios de siglo han aumentado, según los datos de los censos agrarios a 410.567 has. en 1991 — vid. cuadro $\mathrm{n}^{\mathrm{O}} 2$ - extensión ésta que, según otras estimaciones y resultados de recorridos de campo, en la actualidad sería sensiblemente menor y se cifraría en 375.000 has.

En cualquier caso, lo verdaderamente importante es valorar el incremento tan grande operado en los niveles de gasto, puesto que para una superficie de regadío de 137.523 has., a razón de $8.000 \mathrm{~m}^{3} / \mathrm{ha} / \mathrm{año}$, se necesitaban $1.100 \mathrm{Hm}^{3} / \mathrm{año}$, y para 410.567 has., a razón de $5.500 \mathrm{~m}^{3} /$ ha/año se precisan $2.258 \mathrm{Hm}^{3} /$ año. 
Cuadro 2

EVOLUCIÓN DE SUPERFICIES AGRARIAS DEDICADAS A REGADÍO EN EL

SURESTE DE LA PENÍNSULA IBÉRICA DURANTE EL PERÍODO 1904-1991. EN HECTÁREAS

\begin{tabular}{|lrrrrr|}
\hline PROVINCIAS & $\mathbf{1 9 0 4}$ & $\mathbf{1 9 6 4}$ & $\mathbf{1 9 6 9}$ & $\mathbf{1 9 8 0}$ & $\mathbf{1 9 9 1}$ \\
\hline Alicante & 66.522 & 88.700 & 88.200 & 124.500 & 137.114 \\
Murcia & 56.001 & 86.400 & 92.100 & 136.700 & 200.927 \\
Almería & 15.000 & 33.300 & 37.200 & 65.300 & 72.526 \\
\hline TOTAL & 137.523 & 208.400 & 217.500 & 326.500 & 410.567 \\
\hline
\end{tabular}

Fuente: Ministerio de Agricultura. Estadísticas de superficies agrarias.

No faltan los ejemplos de disfuncionalidades creadas al amparo de la expansión de las superficies regadas. Uno, entre otros muchos, que puede ilustrar la espontaneidad de estos procesos y la falta absoluta de planificación, lo constituyen los efectos inducidos del Trasvase Tajo-Segura sobre las tierras de la Cuenca del Segura. Así, cuando en 1968 se iniciaron las obras del acueducto, las previsiones del Anteproyecto General de Aprovechamiento Conjunto de los Recursos Hidráulicos del Centro y Sureste de España, complejo Tajo-Segura, se preveían transformar 90.000 has. en regadío y redotar unas 47.000 has. de regadíos deficitarios. Pues bien, un año antes de iniciarse las obras, en el ámbito que iba a beneficiar el Trasvase la superficie regada ya ascendía a 135.000 has. es decir, tan sólo faltaban 2.000 has. para cumplir con las previsiones del Anteproyecto cuando la obra siquiera se había iniciado.

Como se puede comprobar a la luz de los datos aportados, todas las demandas de agua planteadas por los usos consuntivos han experimentado aumentos muy apreciables durante el presente siglo, concediendo así un valor mucho mayor a los recursos hídricos existentes a disposición del hombre, puesto que éstos se presentan con gran escasez no sólo en cantidad sino también en calidad, más todavía cuando alguna secuencia de indigencia pluviométrica repercute en una disminución de caudales epigeos.

Lo cierto es que los recursos disponibles en las cuencas hidrográficas surestinas a principios de siglo serían del orden de $1.046 \mathrm{Hm}^{3} /$ año que a malas penas se ajustaban a las demandas de aquel entonces, descansando éstas siempre sobre el aprovechamiento de aguas superficiales.

En 1991, las disponibilidades hídricas en condiciones climáticas no sujetas a los efectos de alguna secuencia seca o húmeda, incluirían los mismos recursos de principios de siglo más $565 \mathrm{Hm}^{3} /$ año que se extraen de los sistemas acuíferos subterráneos sin perjudicar el equilibrio de entradas y extracciones. A esas cantidades habría que sumar $246 \mathrm{Hm}^{3} / \mathrm{año}$ que, como promedio anual desde su puesta en funcionamiento, se están travasando desde la cabecera del Tajo. Este volumen ha resultado bastante inferior en los tres últimos años hidrológicos, como lo atestigua el hecho de que en 1994-1995 tan sólo se hubieran cedido $185 \mathrm{Hm}^{3}$ de los cuales casi las tres cuartas partes han sido destinados a abastecimiento urbano.

Atrae poderosamente la atención a tal respecto que los recursos de agua renovables al alcance del hombre, sumados los superficiales $\left(1.046 \mathrm{Hm}^{3} /\right.$ año $)$ y los subterráneos $\left(565 \mathrm{Hm}^{3} /\right.$ año) tan sólo sean $1.611 \mathrm{Hm}^{3} /$ año, mientras las demandas generadas por los distintos usos consuntivos se elevan por encima de $2.500 \mathrm{Hm}^{3} /$ año. Semejante desfase entre exigencias y 
Cuadro 3

DISPONIBILIDAD DE RECURSOS DE AGUA EN EL SURESTE IBÉRICO EN HM`/AÑO EN CONDICIONES CLIMÁTICAS NORMALES

\begin{tabular}{|lcccr|}
\hline CUENCAS & SUPERFICIALES & $\begin{array}{c}\text { SUBTERRÁNEOS } \\
\text { RENOVABLES }\end{array}$ & $\begin{array}{c}\text { SUBTERRÁNEOS } \\
\text { NO RENOVABLES }\end{array}$ & TOTALES \\
\hline RÍO SEGURA & 697 & 160 & 310 & 1.167 \\
DE ALMERÍA & 268 & 253 & 291 & 812 \\
DE ALICANTE & 81 & 152 & 75 & 308 \\
TOTALES PROPIOS & 1.046 & 565 & 676 & 2.287 \\
TRASVASE TAJO-SEGURA & & 246 & & 2.533 \\
\hline
\end{tabular}

Fuentes: Para la Cuenca del Segura se han empleado los datos aportados por el Centro de Estudios Hidrográficos en el año 1967, para un período de 51 años (1912-13 a 1962-63). También se han utilizado otras informaciones de:

MORALES GIL, A.: "Déficit de agua y demandas de transferencias en la Cuenca del Segura". En Planificación Hidráulica en España, Fundación Caja del Mediterráneo, Universidad de Alicante, 1995, pp. 379-398.

MARTÍN-VIVALDI CABALLERO, Mㄹ E.: "Los ríos andaluces". En Geografía de Andalucía, dirigida por G. Cano García, 1992, pp. 245-250.

CONFEDERACIÓN HIDROGRÁFICA DEL SUR.

recursos podría haber sido bastante menor si se hubieran cumplido las previsiones depositadas inicialmente en el Trasvase Tajo-Segura, pues los $600 \mathrm{Hm}^{3} /$ año que se esperaba en la primera de las fases de explotación del acueducto no se han alcanzado nunca. En períodos de sequía como el actual los volúmenes trasvasados han descendido por debajo de 200 $\mathrm{Hm}^{3}$ /año, agravando aún más los efectos de la escasez de lluvias. Consecuencias fatales tiene la única manera que ha empleado el hombre para satisfacer las demandas crecientes que iba planteando, es decir, la sobreexplotación de aguas subterráneas - vid. cuadro $\mathrm{n}^{\mathrm{o}} 3$-.

Se ha producido esta circunstancia, en primer lugar al amparo de la Vieja Ley de Aguas de 13 de junio de 1879, que en modo alguno había previsto el avance tecnológico aplicado a las extracciones de aguas hipogeas. Más tarde, ya con la Nueva Ley de Aguas de 2 de Agosto de 1985 y con la complacencia de unos organismos de cuenca, que no dudan en conceder permisos para hacer nuevos sondeos, este problema se ha visto agravado. Son pues las reservas no renovables de aguas subterráneas las que soportan todo el desfase que existe entre disponibilidades y demandas. Según estimaciones, en condiciones climáticas medias la sobreexplotación de aguas hipogeas se eleva a casi $700 \mathrm{Hm}^{3} /$ año, cantidad ésta que sin duda supera $\operatorname{los} 1.000 \mathrm{Hm}^{3} /$ año cuando disminuyen los epigeos y los trasvasados del Tajo al Segura.

Descensos continuos de niveles piezométricos, en ocasiones superando los 50 metros al año, pérdidas de calidad por aumento de la salinidad, encarecimiento de las extracciones, problemas de subsidencia de los estratos con efectos sobre las edificaciones de un gran número de ciudades de las Vegas Media y Baja del Segura. Y por otro lado, acuíferos que fueron declarados provisionalmente sobreexplotados en 1987 como los de Jumilla-Villena y Sierra de Crevillente que se siguen esquilmando, resumen en pocas líneas la magnitud de un problema de extrema gravedad.

Con mayor motivo aún, la percepción actual de la sequía es muy diferente a la de principios de siglo, ya que el hombre de estas tierras no forzaba las posibilidades del medio natural y aunque a regañadientes, procuraba adaptar sus necesidades a las disponibilidades 
de agua. Ahora, al contrario de entonces, son muchos los medios técnicos que el hombre emplea en su provecho para obtener los recursos de agua que necesita, no reparando incluso en detraerlos de unas reservas que, probablemente, no volverán a restituirse. Se amenaza así su propia supervivencia y la de generaciones futuras, culpando a la naturaleza, en concreto a la sequía, de sus propios errores, cuando es la falta de una planificación económica racional acorde con las disponibilidades naturales de agua y las agenciadas racionalmente por los hombres la causante de estos hechos.

\section{Posibilidades de respuesta del hombre a las sequías}

La falta de una planificación racional de las actividades económicas adecuándolas a los recursos hídricos existentes, obliga a la apertura de una reflexión acerca de las actuaciones que podrían acometerse para aliviar los efectos que las secuencias de indigencia pluviométrica tienen sobre las actividades productivas al acrecentarse, todavía más, el déficit de recursos de agua que las mismas precisan para su desarrollo, hipotecando así sus posibilidades a corto y medio plazo.

\subsection{Reducción de la superficie regada, selección de cultivos rentables e implantación de tecnologías avanzadas de riego}

No ha sido nada habitual, al menos hasta la actualidad, asignar a la utilización de recursos hídricos una valoración de los efectos económicos y sociales generados por los procesos de puesta en valor del territorio producidos a costa del consumo de agua. Más allá todavía, muchas obras hidráulicas, como por ejemplo el Trasvase Tajo-Segura, se han justificado por la rentabilidad económica y social que propiciaban en los territorios beneficiados. Hoy en día, cuando la generación de riqueza debe someterse a otros planteamientos como el respeto a los límites que imponen los recursos naturales, la utilización del agua, por resultar un elemento de gran vulnerabilidad y escasez, precisa de una revisión en los criterios que se establecen para asignar las prioridades de uso. Máxime cuando situaciones extremas de escasez como la que padecen las tierras de estas provincias impiden satisfacer a todos los usuarios en las condiciones de calidad y cantidad exigidas por éstos. La Ley de Aguas de 2 de agosto de 1985 es muy clara al respecto, pues en la jerarquía de utilizaciones concede un lugar destacado a los usos urbanos e, inclusive, a los caudales ecológicos por encima de los agrarios.

La realidad actual, con una Reforma de la Política Agraria Comunitaria en marcha y con una liberalización paulatina de aranceles frente a las producciones hortofrutícolas de terceros países como Marruecos, está demostrando que muchas líneas de producción practicadas por la agricultura de regadío tradicional carecen de rentabilidad económica o la que presentan, invitan cuanto menos a reflexionar sobre si está justificado tanto la forma en la aplicación del riego (sistemas por inundación con eficiencias del 65\%) como la cantidad consumida.

Frente a esta agricultura de regadío tradicional, surgida hace dos o tres décadas y que ocupa unas 250.000 has. en el sureste peninsular, existe otra modalidad de regadío, más intensiva, muy eficiente en el consumo de los recursos, con una buena gestión empresarial y en permanente renovación, no sólo en el proceso de producción sino también en la comercialización, con unas implicaciones económicas y sociales muy grandes.

De esa agricultura de regadío, surgida a mediados de la década de los años setenta y conocida como de vanguardia, existen en Alicante, Murcia y Almería unas 105.000 has., 


\section{Cuadro 4 \\ AGRICULTURA DE VANGUARDIA}

Cultivos hortícolas, flores, y algunos frutales (cítricos y prunáceas).

Superficies cultivadas estimadas en 1994. En Hectáreas.

\begin{tabular}{|c|c|}
\hline Campo de Dalias & $22.500 \mathrm{Has}$ \\
\hline \hline Campo de Níjar y Bajo Andarax & $12.000 \mathrm{Has}$ \\
\hline \hline Bajo Almanzora & $8.000 \mathrm{Has}$ \\
\hline \hline Campos de Águilas y Mazarrón & $6.000 \mathrm{Has}$ \\
\hline Campo de Lorca y Valle del Guadalentín & $14.000 \mathrm{Has}$ \\
\hline Campo de Cartagena & $20.000 \mathrm{Has}$ \\
\hline \hline Bajo Segura & $10.000 \mathrm{Has}$ \\
\hline \hline Campos de Alicante y Elche & $7.000 \mathrm{Has}$ \\
\hline \hline Otras comarcas & $3.000 \mathrm{Has}$ \\
\hline TOTAL & $2.500 \mathrm{Has}$ \\
\hline
\end{tabular}

Fuente: Elaboración propia, apoyada en trabajos de campo, y datos proporcionados por Cámaras de Comercio, Centros de Investigación Agrónomica, agrupaciones de agricultores de vanguardia, y exportadores de frutas y hortalizas.

localizadas preferentemente sobre los llanos y fosas litorales y prelitorales, donde las buenas condiciones climáticas de insolación (unas 3.000 horas), bajo riesgo de heladas, escasez de lluvias que perjudiquen o manchen los frutos, por citar algunas ventajas, permiten cultivar fuera de temporada un gran abanico de hortalizas que en menos de 30 horas, gracias a su proximidad al eje viario de la A-7, son puestas a la venta en los mercados europeos en situación muy óptima para competir con otros países ${ }^{6}$ — vid. cuadro $\mathrm{n}^{\circ} 4$ -

Esta agricultura, aún con las cortapisas impuestas por la sequía, sigue su expansión ${ }^{7}$. Para ello ha sido necesario que sus promotores buscaran el agua en comarcas interiores alejadas de las zonas de cultivo mediante conducciones privadas (minitrasvases), en algunos casos de más de 100 kilómetros de longitud y a veces controlados por aguatenientes. Por otra parte no han dudado en buscar el líquido elemento mediante la construcción de pequeñas plantas desaladoras, sobre todo en los casos donde las empresas agrarias y las comunidades de regantes tienen más implantación como Águilas, Mazarrón y Campo de Cartagena.

Esa carestía de agua obliga a esta agricultura a buscar las plantas de mayor rentabilidad para justificar el coste actual tan elevado de la desalación, entre 40-60 ptas $/ \mathrm{m}^{3}$. Sin embargo, los cultivos de cítricos de los regadíos y las huertas tradicionales no pueden, en ocasiones, pagar estos precios tan elevados a que resulta el agua cuando hay penuria de ella, máxime cuando exigen en ocasiones unas dotaciones por hectárea y año que duplican a las aplicadas a los cultivos antes referidos. Este uso más eficiente del agua, se materializa

6 MORALES GIL, A.: «Escasez y rentabilidad del agua en el sureste de España: agricultura de vanguardia». En Medio Ambiente y Ordenación del Territorio, Fundación Duques de Soria y Universidad de Valladolid, Soria, 1995, (en prensa), 36 pp.

7 Esta expansión ha sido también considerada en el libro editado por el Consejo Económico y Social de la Región de Murcia: «Recursos Hídricos y su importancia en el desarrollo de la Región de Murcia». En Colección Estudios nº 1, Murcia, 1996. 
también en una repercusión socioeconómica en dichas comarcas, pues las producciones de vanguardia llegan a generar un empleo de 5 obreros por cada hectárea y año, mientras que 5 has. de cítricos aseguran el empleo a 1 obrero durante el mismo período.

En 1989 a raíz de la promulgación del R.D. 950/1989 de 28 de julio se preveía la transformación de 69.000 hectáreas de la Mancha Oriental con cargo a los recursos del Júcar, que iban a ser dedicados al cultivo de cereales, de escaso rendimiento económico y social, por lo cual fue considerado por los conocedores de las problemáticas de la agricultura española, como inoportuno y contrario a la Reforma de la Organización Común de Mercado correspondiente, por coincidir con una disminución de las garantías de precios que propiciaban su rentabilidad.

En el sureste ibérico es probable que muy pronto se deban plantear soluciones concretadas en actuaciones para establecer una jerarquía de producciones agrarias que realmente tengan justificado el consumo de agua para el riego necesario. Así, una de ellas para aliviar el déficit de recursos hídricos y los efectos de la sequías descansa en una reducción de las superficies regadas para de esa forma garantizar la supervivencia de las que sean realmente rentables, aunque ello obligará, además, a supervisar un proceso de ajuste estructural y reconversión de las pequeñas explotaciones agrarias dirigidas por agricultores profesionales mediante agrupaciones cooperativas, para así evitar que las grandes empresas del ramo monopolicen a su antojo los sistemas de producción, de comercialización y el mercado del agua.

Capítulo de gran interés estratégico debe tener en ese proceso de modernización de las explotaciones agrarias la difusión de los riegos localizados de alta frecuencia. No sólo se deben aducir las ventajas que tienen esos sistemas en un mayor control y racionalización del gasto de agua para riego, derivado de su mejor eficiencia (un 95\%) frente a los de inundación (un 65\%), sino que resulta también importante el balance de ventajas como nuevo sistema de explotación agraria que permite optimizar las técnicas de riego, de fertilización, de tareas agroculturales y la calidad final del producto.

Por todas estas razones se debe abogar por una ayuda decidida de la administración a este tipo de actuaciones, hasta lograr en estas provincias su total implantación en la superficie a regar que se estime más idónea y rentable para el conjunto de la economía nacional.

\subsection{Racionalización del consumo urbano y depuración de aguas residuales}

Las estrategias de la planificación urbana y turística tampoco han sido solidarias con la limitación que imponía la escasez de recursos de agua, pues no dudaron en acudir a trasvases desde comarcas del interior y otras regiones. Así, la práctica totalidad de los recursos de agua que se consumen en la costa de Alicante son alóctonos, bien de acuíferos ubicados en el Vinalopó y la Montaña, o bien, como sucede con buena parte de la mitad sur dependen de los caudales del Alto Tajo y Alto Segura, distribuidas por la Mancomunidad de los Canales del Taibilla ${ }^{8}$.

Muchas veces, más de las deseables, las expansiones urbanísticas se han realizado mediante tipologías poco acordes con la escasez de agua, siguiendo a veces la política de hechos consumados. Es decir, primero se hacía la urbanización y luego se procedía a buscar el agua para abastecerla. Estas actuaciones obligaron en muchas ocasiones a una intervención de la Administración para subsanar las disfuncionalidades.

8 MORALES GIL, A. y VERA REBOLlO, J.F.: La Mancomunidad de los Canales del Taibilla. Instituto Universitario de Geografía, Universidad de Alicante y Academia Alfonso X El Sabio, Alicante, 1989, 133 pp. 


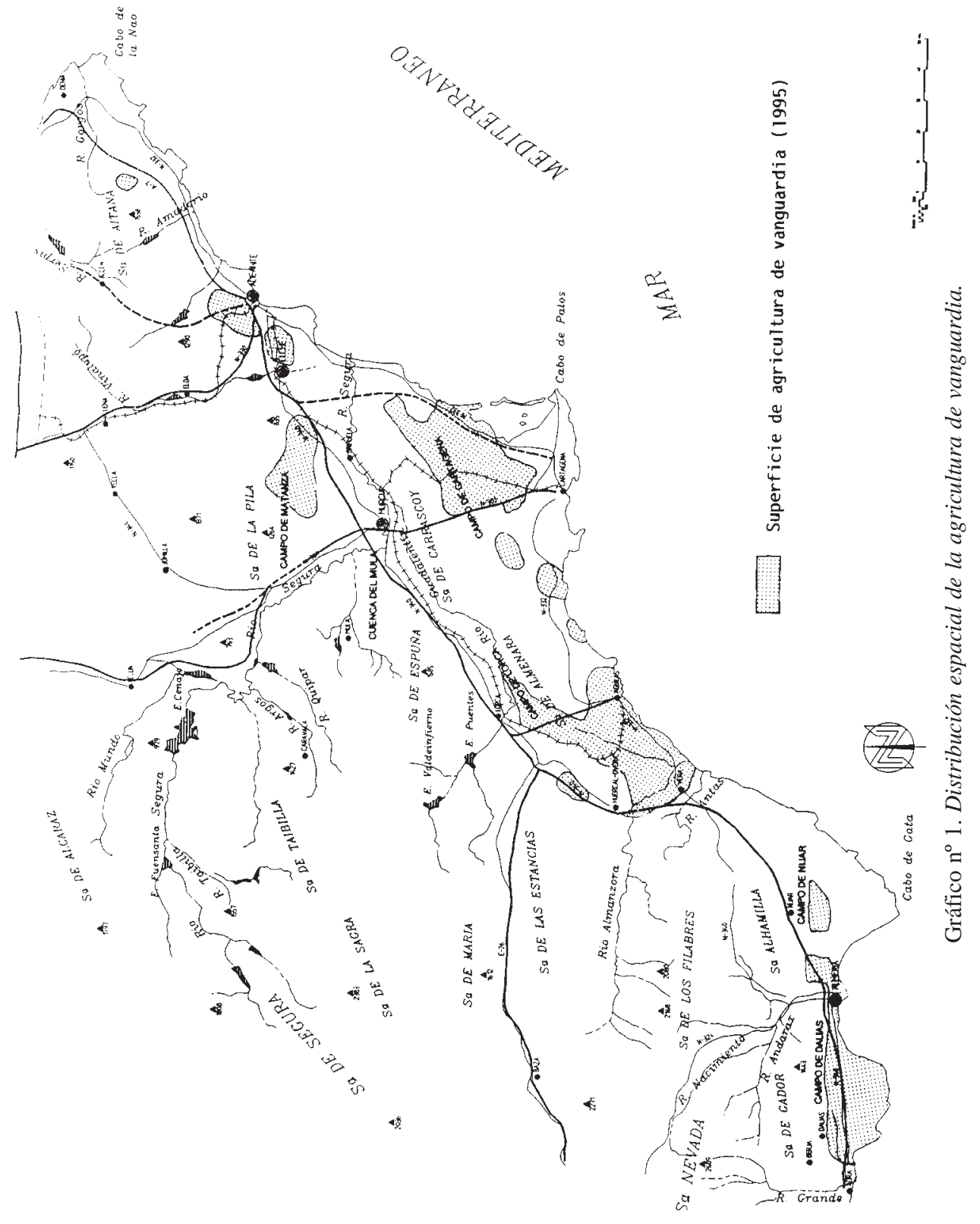




\section{Cuadro 5}

CARACTERIZACIÓN DEL GASTO DE AGUA PARA ABASTECIMIENTO URBANO EN MUNICIPIOS COSTEROS DE LA PROVINCIA DE ALICANTE. 1993

\begin{tabular}{|c|c|c|c|c|c|}
\hline COMARCA & $\begin{array}{c}\mathrm{N}^{\circ} \\
\text { MUNICIPIOS }\end{array}$ & $\begin{array}{c}\mathrm{N}^{0} \\
\text { CONTADORES }\end{array}$ & $\begin{array}{c}\mathrm{M}^{3} \\
\text { CONSUMIDOS }\end{array}$ & $\begin{array}{c}\mathrm{M}^{3} \\
\text { DEPURAD. }\end{array}$ & DEPURACIÓN \\
\hline Marina Alta & 8 & 60.000 & 11.251 .781 & 144.000 & $\begin{array}{l}\text { - } 4 \text { municipios sin depuradora } \\
\text { - } 1 \text { que no funciona } \\
\text { - } 3 \text { funcionan } \\
\end{array}$ \\
\hline Marina Baja & 7 & 107.000 & 21.124 .356 & 12.167 .879 & $\begin{array}{l}\text { - } 1 \text { sin depuradora } \\
\text { - } 1 \text { que no funciona } \\
\text { - } 5 \text { funcionan } \\
\text { - Urbanizaciones sin } \\
\text { alcantarillado }\end{array}$ \\
\hline $\begin{array}{l}\text { Campo de } \\
\text { Alicante }\end{array}$ & 5 & 192.730 & 40.487 .006 & 14.566 .121 & $\begin{array}{l}\text { - Todos los municipios están } \\
\text { conectados a las depuradoras de } \\
\text { Orgegia y Barranco de las Ovejas }\end{array}$ \\
\hline $\begin{array}{l}\text { Bajo Vinalopó } \\
\text { Bajo Segura }\end{array}$ & $\begin{array}{l}2 \\
7\end{array}$ & $\begin{array}{l}90.000 \\
86.400\end{array}$ & $\begin{array}{l}19.453 .580 \\
14.946 .634\end{array}$ & $\begin{array}{l}3.650 .466 \\
9.274 .300\end{array}$ & $\begin{array}{l}\text { - } 2 \text { depuradoras } \\
\text { - Todos cuentan con depuradora } \\
\text { - Una media del } 40 \% \text { de } \\
\text { agua perdida o no facturada }\end{array}$ \\
\hline TOTALES & 29 & 536.130 & 107.263 .357 & 39.802 .766 & \\
\hline
\end{tabular}

Fuente: Elaboración propia a partir de encuestas realizadas en ayuntamientos y en entidades de abastecimiento de agua potable para la realización del proyecto MUNRES sobre revitalización de municipios con turismo residencial, encargado al Instituto Universitario de Geografía de la Universidad de Alicante por parte de la Diputación Provincial de Alicante.

Modelos de urbanización de baja densidad, con jardines, piscina propia, con consumos que superan los 500 1/hab./día, sistema de saneamiento inexistente, diseños de la red de agua potable nada apropiados y costosos, con elevadas fugas, han experimentado un proceso expansivo que también ha repercutido en un aumento espectacular de los niveles de gasto de agua potable en estos municipios costeros. Frente a éstos, hay que destacar las ventajas de otros donde la tipología urbanística dominante es concentrada de alta densidad y con abundante oferta hotelera, activada casi todo el año, con elevados rendimientos económicos y sociales, caso de Benidorm. Aquí, las redes de distribución de agua potable y de saneamiento son más eficientes, y el nivel de gasto por habitante y día es, comparativamente, más reducido que los casos anteriores. De hecho, en este tipo de oferta, los valores añadidos que genera el agua son muy elevados y, sin duda, estos ayuntamientos pueden acudir al empleo de técnicas avanzadas para la obtención de recursos mediante la desalación de agua marina. Se hace necesario que la totalidad de municipios cuenten con infraestructuras eficientes para la depuración de aguas residuales, para que una vez recicladas puedan ser reutilizadas por la agricultura. En vísperas del siglo XXI son numerosas las urbanizaciones sin alcantarillado, con pozos negros, con emisarios submarinos, sin conexión con depuradoras que no funcionan o lo hacen incorrectamente, por lo cual de los 
$107 \mathrm{Hm}^{3}$ que se consumieron en 1993 en el litoral alicantino tan sólo se recuperaron $39,8 \mathrm{Hm}^{3}$ - vid. cuadro $\mathrm{n}^{\circ} 5$ - . De nuevo, parece obligado demandar una mayor seriedad y rigor en la gestión de unos recursos de agua que correctamente depurados pueden resultar vitales, más todavía en situaciones de indigencia pluviométrica, para su reutilización en agricultura.

\subsection{Aportación de recursos foráneos}

Todas las alternativas que se han barajado para racionalizar al máximo la utilización de los recursos disponibles en el sureste peninsular son incapaces por sí solas de aportar todos los volúmenes de agua que precisan las demandas actuales, máxime cuando en situaciones de sequía el déficit existente se agudiza y provoca un aumento de la sobreexplotación de los acuíferos subterráneos. Se demuestra así que una planificación de la utilización del agua no puede estar desconexa de las economías regionales de estas provincias y, por añadidura, de la estatal, donde cada vez más se apoyan e incentivan sectores productivos de gran vocación exportadora y de gran interés social, como la mayoría de los sectores que predominan en este territorio. Ese interés general debe acompañarse, en la misma medida y en coordinación con la planificación económica, por una de carácter hidráulico a escala estatal que garantice la satisfacción de las demandas actuales y mitigue los efectos de las sequías sobre los recursos de agua disponibles en las diferentes regiones peninsulares, acudiendo para ello a mecanismos de solidaridad interregional en la distribución de riqueza y agua.

La escasez hídrica en las tierras surestinas y su agravamiento por efecto de episodios de sequía, sólo puede ser abordado garantizando la aportación de caudales foráneos, bien del Alto Tajo, o bien de otras cuencas excedentarias vecinas. Pieza clave, qué duda cabe, resulta la aprobación del Plan Hidrológico Nacional y la ejecución del controvertido Sistema Integrado de Equilibrio Hidráulico Nacional donde descansa toda la atención y los intereses encontrados de las regiones cedentes de recursos y las receptoras.

Para este territorio, de prolongarse la seca actual, la única esperanza que cabe mantener es que se sigan trasvasando caudales desde el Alto Tajo, al menos en las cantidades de estos últimos años, y que se acorten al máximo posible los plazos (horizonte del año 2012) del todavía Anteproyecto del Plan Hidrológico Nacional, para satisfacer las demandas de transferencias desde otras cuencas a las del Segura y Júcar, cifradas por los dos Organismos de Cuenca en casi $2.000 \mathrm{Hm}^{3} / \mathrm{añno}^{9}$. Rebajadas en más de $500 \mathrm{Hm}^{3}$ en las propuestas de modificación del citado Anteproyecto. Se recoge así, sólo en una pequeña parte, la oposición de las cuencas cedentes, de grupos ecologistas, e incluso del Ministerio de Economía y Hacienda por motivos presupuestarios y por considerar necesario antes un Plan de Regadíos $^{10}$. Hay que subrayar, asimismo, el escaso interés existente por explicar la estrecha vinculación entre el Plan Energético Nacional y el PHN pues el primero, ya desde 1912, ha condicionado las perspectivas de expansión de los regadíos y la aplicación del agua a otros usos diferentes a la producción hidroeléctrica.

9 En estas previsiones de las confederaciones hidrográficas del Júcar y Segura se incluyen también las necesidades de la Cuenca del Río Almanzora.

10 GIL OLCINA, A.: "Conflictos autonómicos sobre trasvases de agua en España". En Investigaciones Geográficas, nº 13, Instituto Universitario de Geografía, Universidad de Alicante, Murcia, 1995, pp. 17-28. 


\subsection{La desalación de agua del mar}

Agotadas las alternativas que se ofrecen para combatir los efectos de las sequías sobre la disminución de recursos hídricos, la única opción viable frente a esas situaciones es utilizar el agua disponible en cada momento con el máximo cuidado, no dudando en priorizar usos si hiciera falta. Al margen de ello, la seca que se inició en el otoño de 1993, con tan sólo dos años de vigencia, ha vuelto a despertar de nuevo las esperanzas que desde hace años habían suscitado las técnicas de la desalación de aguas salobres o del mar.

La construcción de desaladoras se revela, por tanto, como una de las alternativas, no ya de futuro, sino de presente, para aquéllos que pueden afrontar los costes de amortización y de funcionamiento, los cuales, por su elevado precio tan sólo están al alcance de las agriculturas más rentables y de los usos urbanos y del turismo, donde la seguridad en el suministro es vital para sus intereses.

Las técnicas de desalación más empleadas en la actualidad son:

1. Por ósmosis inversa, con utilización de membranas para el filtrado de elementos salinos, lo que exige un consumo de energía entre 6 y $8 \mathrm{Kw} / \mathrm{m}^{3}$ es decir, algo menos de $60 \mathrm{ptas} / \mathrm{m}^{3}$ aunque no logran producir un agua absolutamente potable. De hecho, son bastantes los incentivos que la administración destina a la construcción de plantas desaladoras que hacen viables algunos de estos proyectos.

2. Por compresión de vapor, donde se obtiene un agua de excelente calidad aunque el consumo de electricidad asciende de 8 a $10 \mathrm{Kw} / \mathrm{m}^{3}$ lo que supone algo menos de $100 \mathrm{ptas} / \mathrm{m}^{3}$, pero los precios de este sistema se pueden abaratar a casi la mitad si se emplean las energías residuales de las centrales térmicas, mediante el llamado proceso de cogeneración. Así, el agua para agricultura podría servirse a precios que oscilarían de 40 a $60 \mathrm{ptas} / \mathrm{m}^{3}$ y la destinada a usos urbanos no excedería de $100 \mathrm{ptas} / \mathrm{m}^{3}$.

En Mazarrón el pasado mes de noviembre fue inaugurada una planta que ha costado 786 millones de pesetas, con una capacidad de transformación anual de $5 \mathrm{Hm}^{3}$ de aguas salobres alumbradas en pozos. Con el agua producida, mezclada con otras de baja salinidad, se riegan 3.500 has. de cultivos hortícolas adscritas a la Comunidad de Regantes de esta localidad.

En la Vega Baja son ya seis las que se han proyectado para diversas comunidades de regantes y otras tantas para los Campos de Níjar y Dalías. De mayor transcendencia resultan los proyectos del MOPU para tres plantas desaladoras para abastecimientos urbanos en Almería, Cartagena y Alicante, con una capacidad anual de $100 \mathrm{Hm}^{3}$ entre las tres. Como igualmente es destacable del interés que ha despertado a las compañías eléctricas, la firma en el mes de noviembre último de un Protocolo entre ENDESA y la Comunidad Autónoma de Murcia para estudiar la viabilidad de un proyecto para construir en la costa de Murcia una serie de desaladoras, con una inversión de 400.000 millones de pesetas que en 1 ó 2 años podría producir $180 \mathrm{Hm}^{3}$ y en cinco unos $350 \mathrm{Hm}^{3} / \mathrm{añon}^{11}$.

Aún así, pese a estas previsiones, los elevados costes en energía que exigen los procesos de desalación plantean bastantes reservas con respecto a estas técnicas, por la hipoteca que supone tanta subordinación de fuentes de energía de las que se carece, por lo que parece aconsejable, a menos que se abaraten los precios de ésta, no depender en exceso de las aguas producidas mediante estos procedimientos, favoreciendo sólo su utilización en

11 La noticia fue recogida durante varios días por los diferentes medios de comunicación locales y nacionales durante el mes de noviembre de 1995. 
aquellas actividades productivas capaces de afrontar los costes de amortización y obtención del agua, hecho que propiciaría la creación de una reserva estratégica que aliviase situaciones de sequía extrema.

\section{Reflexión final}

A la vista de estos comentarios sobre las sequías, parece razonable admitir que en lo sucesivo sería ideal adaptar en cada momento la demanda de los diferentes usos consuntivos y los procesos de puesta en valor del territorio, a los recursos de agua renovables disponibles dentro de la propia región, complementándolos con las aportaciones de los trasvases que se estimen viables y la desalación de aguas dentro del Plan Hidrológico Nacional. Esta actuación cobra mayor valor y urgencia si se tiene en cuenta que los embalses de la cuenca del Segura ya no sirven para almacenar aguas excedentarias los años de lluvias por encima de la media, pues año tras año, desde 1978, se observa cómo las demandas (agrarias y urbanas) van siempre por delante de los recursos disponibles. De ahí que en la actualidad la función de éstos quede reducida a la laminación de avenidas, al ser impedida la restitución de las reservas y su capacidad de regulación plurianual, aunque la sequía remita, por la falta de una planificación real que ajuste disponibilidades y demandas.

Por otro lado, para amortiguar los efectos de futuras sequías, que sin duda las habrá, será de gran valor contar, en muy breve plazo, con la ayuda puntual de plantas desaladoras para atender a las demandas estacionales extraordinarias que se produzcan y, sobre todo, para paliar los efectos de las secuencias de indigencia de lluvias en la disminución de recursos de agua que se consideran de interés estratégico para economías productivas de gran rentabilidad, como turismo, industria y agricultura de vanguardia, capaces ya hoy en día de asumir los elevados costes energéticos que exige la producción de agua por estos métodos artificiales.

En estas actividades económicas la falta de agua, aunque fuera puntual, en las cantidades y calidades que se precisan en el proceso productivo, podría arruinar todos los esfuerzos que se están llevando a cabo para ser competitivas en unos mercados internacionales cada vez más agresivos, lo que pondría en peligro unos sectores económicos de alto interés estratégico para los intereses generales del Estado por la gran cantidad de divisas que generan y por la abundante mano de obra empleada en ellos.

Si se hiciesen realidad las previsiones anteriormente expuestas, resultaría que los habitantes de estas provincias con su imaginación, su decisión y su capacidad de innovación permanente, habrán ganado una pequeña batalla más a la aridez, al ser ésta una limitación natural que secularmente hipoteca su futuro desarrollo. 